\title{
DOS ASPECTOS DE LA MUJER EN BUSCA DE SI MISMA $Y$ EN CONTRA DE LA SOCIEDAD
}

POR

\author{
MICHELE S. DAVIS
}

Ohio State University

Dos autoras argentinas penetran la frustración de la mujer forzada a: oponerse al mundo para que sigan brillando los ideales que impulsan su propia naturaleza como ser femenino y humano en las obras Yo me divorcio, papá, de Malena Sándor, en la que una señora acaba de separarse de su marido, y Cimbelina de 1900 y pico, de Alfonsina Storni, que trata de una recién casada.

Rafael Alberto Arrieta, en su Historia de la literatura argentina, incluye a Malena Sándor dentro de los autores cuyas obras reflejan el sentido universal, atribuyéndole «la dignidad artística, el ingenio y el largo éxito ${ }^{1}$. La pieza ya citada ejemplifica este punto de vista: E1 doctor Aguirre ha adquirido cierta fama durante su carrera en el Senado, oponiéndose: al divorcio. Defiende su posición, basada en la necesidad de mantener la. estabilidad social y en varias ideas religiosas. Su hija, reconociendo el daño psicológico sufrido por la mujer atrapada en un matrimonio infeliz, finge separarse de su esposo para abrirle el corazón a su padre ante una cuestión humana de tanta envergadura. Lo convence de la importancia de tal derecho, sin que su padre se dé cuenta de que ella es una señora verdaderamente dichosa en su casamiento.

El problema de la mujer presa de una sociedad completamente dominada por hombres brota de la poesía, así como de los dramas de Alfonsina Storni. Por eso, Nira Etchenique define su teatro: «El-conflicto social. que ha aparecido vivo y desnudo en sus versos, toma nombres, carne $\mathrm{y}$ diálogo...» ${ }^{2}$, En efecto, en Cimbelina, la protagonista lucha contra las

1 Rafael Alberto Arrieta, Historia de la literatura argentina, tomo $\mathrm{H}$ (Buenos Aires: Ediciones Peuser, 1959), p. 603.

${ }^{2}$ Nira Etchenique, Alfonsina Storni (Buenos Aires: Editorial la Mandrágora, 1958), p. 11. 
debilidades de tres hombres: la actitud patriarcal de su padre, el complejo de inferioridad de su medio hermano y las avanzadas amorosas de un hombre egoísta. María Elena se casó con Héctor contra la voluntad de la familia, y por eso su papá, un ministro poderoso dentro del gobierno, propicia el destierro de su propio yerno. Durante la ausencia de Héctor, dos hombres extreman sus atenciones con la triste novia: Maneco, quien, como medio hermano, se considera con derecho a sus favores, y José, el primo de Héctor, quien cree que no hay mujer que pueda resistírsele. A pesar de su inquietud particular, María Elena, comprendiendo los designios de los tres, mantiene su equilibrio psicológico hasta que se reúne con su marido al final de la obra.

El punto de partida de las dos dramaturgas es diferente; también varía su manera de presentar la rebelión de la mujer: Andrea, creada por Malena Sándor, defiende sus derechos innatos, lanzando teorías frías y lógicas; mientras que María Elena, el personaje principal en la obra de Alfonsina Storni, manifiesta su agonía personal y su aflicción interior.

Andrea, viéndose víctima de las generalizaciones severas de su padre, le responde del mismo modo para que él la comprenda. A través de los años, el doctor Aguirre ha basado su misión en «la moral, la religión, la sociedad; todas esas tradiciones que constituyen las raíces más hondas de la humanidad» ${ }^{3}$. Su hija, atacando estos convencionalismos, propone el amor como el único valor capaz de dirigir el curso de la vida. Sin embargo, su padre, sin comprender esta emoción, la sustituye con la doctrina del matrimonio como sacramento indisoluble, y ella le hace ver que en toda ley hay excepción. Insiste en que hay que ser flexible en el tratamiento de la gente; pero el político está obsesionado con la idea de un sólido orden social al que perjudica el divorcio; concepto no compartido por su hija, quien explica: «El divorcio no va a perturbar la serenidad del matrimonio bien realizado» (p. 21). La más violenta explosión patriarcal ocurre cuando él interpreta la separación de sus hijos como la destrucción de su propia carrera, terminando con: «En todo caso, me debes el respeto a mi personalidad» (p. 21). A la cual dirige ella tres flechas: «¿Respeto es callar?» (p. 21).

A pesar de la fuerza de las respuestas de su hija, el senador reduce las emociones humanas a la frialdad del razonamiento, prefiriendo que ella se someta a la voluntad de su marido. Pero la víctima, con la misma inflexibilidad glacial, indicando que todo está resuelto, reitera que se di-

${ }^{3}$ Malena Sándor, "Yo me divorcio, papá», Teatro completo (Buenos Aires: Editorial Talía, 1969), p. 20. Las páginas de las otras citas de esta obra aparecen entre paréntesis. 
vorcia. Oponiéndose a sus sentimientos, Aguirre le niega su independencia, empujándola hacia el papel tradicional de la sumisión femenina, resignada, despertando otro comentario impersonal de Andrea: «Es mucho peor hacer cada uno su vida y engañar a la sociedad con la apariencia de una comunidad mentida» (p. 24). Aun viendo que esta mujer está decidi$\mathrm{da}$, el senador lanza su teoría más inflexible: «El matrimonio tiene que ser un acto responsable y definitivo que no admita alternativas de ninguna especie» (p. 25). Sin embargo, Andrea contradice su actitud inhumana: "Qué poco cuesta hacer más fácil el camino de la humanidad...» (p. 27).

Aunque el doctor Aguirre es un hombre inteligente, analiza al mundo en términos de la disciplina y la subordinación de la mujer. Su hija, sin embargo, se sitúa al otro lado de la cuestión, preocupándose por los sufrimientos e implorando a su padre: «Desciende de tu inteligencia y háblame con el corazón» (p. 24). De ahí que ella eleve la cuestión del divorcio a un sentimiento general: «... me surge un grito de rebelión como si fuera el de todas las mujeres juntas» (p. 19). Reconociendo también que somos víctimas de nuestras propias debilidades, define el divorcio como «una tabla de salvación a los que han equivocado su destino...» (p. 21). Proyectando su vista más allá de su situación personal, le ruega a su padre que silencie su oposición al divorcio «en nombre de todas las mujeres...» (p. 24).

En general, los diálogos de esta obra carecen de vitalidad emocional, poniendo en primer plano las teorías que favorecen los derechos de la mujer. Por el contrario, las conversaciones de María Elena del drama de la Storni señalan sus sentimientos personales en todo momento. Descubriendo que su padre ha desterrado a su marido, la firmeza de su amor se convierte en la meta principal de su existencia. Manteniéndose segura ante su concepto del verdadero amor, manifiesta una fuerza y un equilibrio interior que la hace rebelarse en contra de la actitud constante del hombre, proclamando sus derechos como mujer. Cuando su padre trata de subyugarla no con la lógica, sino con la frase "Soy jefe» ${ }^{4}$, María Elena lo rechaza con: «Tengo otra profesión: mi marido» (p. 23), reafirmando su posición como individuo en la sociedad.

Más tarde, este personaje, intentando ejercer su independencia, piensa organizar su propio negocio: «Yo, hija del ministro... pondré una casa de modas...» (p. 28); pero el doctor Gutiérrez la domina otra vez: la amenaza con mandarla a la cárcel. Esta conversación despierta otro ata-

4 Alfonsina Storni, «Cimbelina en 1900 y pico», Dos farsas pirotécnicas (Buenos Aires: Cooperativa Editorial, 1931), p. 23. Las páginas de las otras citas de esta obra aparecen entre paréntesis. 
que, no de su padre, sino de su medio hermano. Maneco, un tipo débil, adopta la misma actitud expresada por su padrastro, pensando que así debe tratarse a las mujeres. Además, su madre lo ha convencido de que merece el amor de María Elena, y a pesar de que su media hermana no lo ama, piensa dominarla con groserías como: «Te escupiré a la cara» (p. 28), o con expresiones superficiales: «Una mujer siempre es una mujer, y un hombre siempre es un hombre...» (p. 29). Ante estas tonterías, la agonía de María Elena es evidente: "iDios mío, Dios mío! Padre, ihe sido insultada!» (p. 29).

Sin embargo, su frustración no tiene efecto ninguno, ya que su medio hermano insinúa que es siempre posible comprar los favores de la mujer. Ante lo cual, expresa ella su indignación, echándolo de su presencia. Desesperada, le pide protección a su padre; pero, con toda severidad, el doctor Gutiérrez la echa de la casa, provocando una explosión conmovedora e irónica a la vez: «¡Papá... papá... llevo tu sangre en mis venas... tu sangre! La sangre es un lazo indisoluble... Yo no soy un ser ovíparo...» (p. 29).

Huyendo de la dominación de estos dos hombres, se enfrenta a otro personaje masculino que busca su precio. José, convencido de que puede conquistar a María Elena durante la ausencia de su marido, le envía regalos, incluyendo flores, bombones y libros. Este tipo donjuanesco nunca toma en cuenta a la personalidad femenina; sólo le interesan los aspectos físicos y el aumentar su lista de conquistas amorosas:

Treinta años... rubia... casada... 18 años, rubia también... ni casada ni soltera; clase intermedia... 26 años, pelirroja, ojos verdes, piel muy blanca, hipercasada, dos divorcios (p. 31).

Colecciona mujeres, pero sólo rubias, y así, las mujeres se transforman en objetos cuyos valores dependen del color del pelo. Las morenas son algo ásí como un «subtipo», quedando en segundo lugar. Degrada a la mujer aún más, reduciéndola a un objeto inanimado: «que los hombres escogemos a las mujeres como a las frutas; forma, color, madurez, perfume...». (p. 57).

Vista esta actitud, no nos extraña que este tipo se acostumbre a comprar los favores femeninos. La reacción de María Elena ante todos los regalos es sumamente humana:

¡Flores! Oh, el amor es belleza, perfume... ¡Bombones!... la lengua femenina es débil... necesita ser alimentada con azúcar, chocolate... miel... ¡Libros! (hojeándolos). ¡Heroínas de amor! iIdilios!... ¡Oh, el buen ejemplo!... (p. 65). 
Después de aparentemente enumerar sus propias debilidades, dirige su comentario a la conducta del hombre, dándose cuenta de que él piensa tentarla: «iY tras los heraldos, claro está, el caballero!...» (p. 65).

La segunda etapa de la conquista presupone desilusionar a María Elena en cuanto a la moral de su marido:

Está muy lejos de ser el hombre recto y disciplinado que usted ha conocido, María Elena; siento mucho decírselo, pero usted es una mujer fuerte, honesta, pura, y por consiguiente merece conocer siempre la verdad (p. 69).

Añade después que acaba de recibir una carta de un amigo, describiendo los nuevos escándalos de Héctor en compañía de mujeres malas. Comprendiendo que este hombre quiere subyugarla por medio de mentiras, se yergue, gritando:

¡Mentiras! ¡Calumnias! ¡Infamias! ¡Es usted un miserable! ¡Un cobarde! ¡Un traidor! ¡No le creo una palabra de todo lo que me ha dicho!... ¡Desmiéntalo, desmiéntalo! O... (p. 70).

Viendo que ha fracasado este aspecto de su designio, José hace por seducirla, impresionándola con ejemplos de sus proezas varoniles. Describe su habilidad para nadar cuatro horas sin descanso. Sin embargo, María Elena comprende las intenciones de José, y cuando lo invita a tomar té a la una de la madrugada, para protegerse de él, utiliza un tono de burla; pero José, como es tan vanidoso, la toma en serio. Cuando espera la llegada de este Don Juan, ella se siente nerviosa. José, por su parte, seguro de sí mismo y ciego a todo, se cree vencedor. En medio del caviar y del champaña, en medio de las palabras más almibaradas para conquistar a María Elena, José, cuando está más entusismado, es vencido por un grupo de jóvenes bulliciosas que cantan a coro «el arroz con leche» * y giran alrededor de él. Lo atrapan, por ironía, como en un círculo envolvente que simboliza la actitud de José para con las mujeres que ha tratado de seducir. Esta vez, iel conquistador resulta conquistado, o más bien desenmascarado! Así dio Alfonsina énfasis al triunfo de la mujer en su papel de victimaria en una sociedad llena de prejuicios ancestrales, que la hace víctima del hombre, que es menos hombre con su actitud donjuanesca.

De todos modos, a pesar de varias desemejanzas, las protagonistas de las dos obras son idénticas en esencia, pues se mantienen firmes ante sus

* Una canción folklórica infantil. 
ideales. Andrea quiere que todo el mundo tenga la oportunidad de escoger su propio destino. Y María Elena confía en «el amor, mundo; en la juventud, en el ideal, en la belleza, en la alegría, en el optimismo» (p. 38). Con estas creencias y con plena confianza en sí mismas, estas dos mujeres tratan de elevar al ser humano en general y a las mujeres en particular hacia un conocimiento de sus peculiaridades dentro del universo, ya que la existencia plasmada debe basarse en nuestra capacidad de sentir, pensar y actuar con toda sinceridad en busca del propio yo y de la propia vida. 